\title{
Improvement of ecological tourism on the principles of sustainable economic development
}

\author{
Utegaly Shedenov ${ }^{1}$, Oleg Litvishko ${ }^{2}$, Beket Kazbekov ${ }^{1}$, Maiya Suyunchaliyeva ${ }^{1 *}$, and \\ Kairzhan Kazbekova ${ }^{1}$ \\ ${ }^{1}$ Al-Farabi Kazakh National University, 050040, Almaty, Kazakhstan \\ ${ }^{2}$ Plekhanov Russian University of Economics, 117997, Moscow, Russia
}

\begin{abstract}
The article reveals the essence and characteristics of ecotourism, identifies its problems and determines the directions and objectives of its development, provides comparative indicators of the number of protected areas in different countries of the world and the income that countries receive from tourism in specially protected natural areas. The main problems and aspects of its development in the context of recreational geography and tourism are highlighted, such as the lack of a common national concept for the development of rural tourism or the lack of a clearly formulated state policy. There are no standards and rules applicable to rural tourism, nor qualified personnel, knowledge and experience in the service of foreign and domestic tourists. There are no normative legal acts in the field of ecological tourism, which is aggravated by the reluctance and inability to effectively use private recreational resources. In this study was done key findings.In this article the author raises questions related to the current state of ecotourism and prospects of its development. Over the past quarter century, both supply and demand for ecotourism have increased significantly. At the same time, ecotourism, as a special form of tourism development, is increasingly recognized and legitimized as a means of achieving sustainable development in destination areas.
\end{abstract}

\section{Introduction}

Tourism is one of the largest industries in the world. In recent years, the tourism industry has been growing very rapidly. The tourism industry is often considered as an industry without chimneys. In other words, this industry is seen as an environmentally friendly industry. However, tourism is said to be an enemy of culture and the environment. It infects pristine cultures, causing the effects of cultural value erosion and, often, uses pure cultures for the own benefit of tourists. Despite its negative environmental, social and cultural impacts, it is virtually impossible to abandon tourism. Tourism is so close to the human psyche that we cannot imagine human life without tourism. Of course, its negative consequences must be properly addressed and it must be turned into an industry with social,

\footnotetext{
*Corresponding author: maya-timur@mail.ru
} 
cultural and environmental values. S. Ziyadin et al researched the necessary conditions which are surved of the regional location of potential agro-tourism facilities, consideration of recreational systems at the oblast level, the state of the socio-economic sphere of the regions, the study of the state of the rural infrastructure, the development of industry in the regions, and the study of cultural and historical significance.[1]

Madiyarova, A., et al wrote about modern trends in digitalization of tourism industry, how it is developed. [2]

In particular, ecotourism has the following characteristics [3]:

1. Fair, inefficient behaviour of visitors;

2. Local culture sensitivity and assessment; biodiversity;

3. Supporting local environmental efforts;

4. Sustainable benefits for local communities;

5. Participation of local authorities in decision-making;

6. Educational components for travelers and locals;

7. Communities.

Ecotourism, according to the International Ecotourism Society, is defined as "a responsible journey to natural areas that preserves the environment, supports the well-being of the local population and includes interpretation and education". Education should cover both staff and guests. As an increasingly important economic and social activity, tourism enhances and at the same time reinforces the negative impact on the environment. Since the beginning of the 1980s, ecotourism has become one of the most popular forms of travel around the world, with the aim of protecting the environment: in ecotourism, travellers use only eco-friendly transport, organize huts only in designated areas, collect berries and herbs in permitted areas, and build accommodation facilities using only harmless materials. Despite the efforts of the international scientific community, the term "ecotourism", as well as the classification of types of ecotourism, still has no unambiguous concept, the only correct and recognized interpretation [4]. Ecotourism is aimed at people traveling for different purposes: from short-term recreation in nature to scientific research of natural and ecological character. For planning, rational organization and management of all kinds of ecotourism, it can be systematized according to different criteria: the purpose of the trip, the main objects visited, a group of travelers, the duration of the trip, recreational activities, etc. The main objects of ecotourism in the classical model are relatively intact natural complexes and their components. In the last two decades, natural-anthropogenic and anthropogenic landscapes have become ecotourism objects due to the knowledge of nature management and ecology. This direction includes a wide range of ecotourism, ranging from historical and natural excursions to eco-educational, to excursions to industrial enterprises [5].

In Kazakhstan, ecotourism began to develop in 1995, and after the adoption of the law "On tourism activity in the Republic of Kazakhstan" from 13.06.2001 № 211, it officially received the status of one of the most priority tourism industries [6]. Unfortunately, in the Republic of Kazakhstan, the development and scientific study of one of the most promising areas of tourism began to manifest itself only with the approaching of the new millennium. Kazakhstan possesses rich natural and cultural resources and offers many opportunities for tourism development and development, especially such niche segments as ecological, cultural and adventure tourism. To date, there are separate scientific works and practices that make up the problem of ecotourism development in the country, but there are no studies that would reveal the definition, basic principles and mechanisms of ecotourism, as well as different models of ecotourism, as in foreign experience [7].

The relevance of the research topic is that the tourism sector offers many destinations, tours and attractions. As a consequence, this has led to serious environmental problems, such as wastewater, garbage, land use, shrinking forest cover, changing coastlines, habitat 
loss for many species, etc. Today, ecotourism provides the best way to manage resources and offers an ecological ideology. It also offers important links between conservation and restoration.

Eco-tourism has become one of the most viable economic options for the global tourism industry. Thus, another important goal of this sustainable form of tourism is to facilitate the implementation of various destinations and increase the competitiveness of various enterprises associated with this sector. This helps these organizations to continuously flourish and provide long-term benefits to those interested in eco-tourism.

The object of the study is ecotourism in Kazakhstan.

The subject of the study is the territorial peculiarities of the use of protected areas for the development of ecotourism in Kazakhstan.

The aim of the study is to study ecotourism and its development, to identify the main directions in which ecotourism can develop in Kazakhstan.

Objectives

(1) Define the theoretical basis for the development of ecotourism and examine its role in the tourism system

2. Make an analysis of the environmental and tourist potential of Kazakhstan and identify its potential

3. Identify eco-tourist areas as eco-tourism development centers in Kazakhstan

4. Develop recommendations for further development of ecotourism.

\section{Literature review}

Ecotourism, according to the International Ecotourism Society [8], is defined as "a responsible journey to natural areas that preserves the environment, supports the well-being of the local population and includes interpretation and education". Education should cover both staff and guests. As an increasingly important economic and social activity, tourism enhances and at the same time reinforces the negative impact on the environment [9]. Since the early 1980s, ecotourism has become one of the most popular forms of travel around the world, with the aim of protecting the environment: in ecotourism, travellers use only environmentally friendly transport, organize huts only in designated areas, collect berries and herbs in permitted areas, and build accommodation facilities using only harmless materials [10]. Ecotourism, according to the International Ecotourism Society [11], is defined as "a responsible journey to natural areas that preserves the environment, supports the well-being of the local population and includes interpretation and education". Education should cover both staff and guests [12]. As an increasingly important economic and social activity, tourism enhances and at the same time reinforces the negative impact on the environment [10]. Since the early 1980s, ecotourism has become one of the most popular forms of travel around the world, with the aim of protecting the environment: in ecotourism, travellers use only environmentally friendly transport, organize huts only in designated areas, collect berries and herbs in permitted areas, and build accommodation facilities using only harmless materials [13].

Recently, the world has paid special attention to sustainable development of tourism [14], which is a key policy objective at the global national and regional levels [15]. Sustainable tourism development is characterized by a strong emphasis on the environmental impact of short- and long-term tourism development [16]. As an important area of research on sustainable tourism development, the environmental safety of tourism is gaining prominence [17]. However, with the rapid development of the tourism industry worldwide, the negative impact on the environment is increasing. These negative consequences not only affect the self-organization and environmental safety of tourism enterprises [18]. Sustainable development of tourism should be achieved when natural 
resources and ecological environment are in balance and there is no threat or risk. How to maintain tourism and environmental security within the international community.

According for experts marks there are several Kazakhstan scientists who gave their position to this theme. Among of them Ziyadin, S., Borodin, A., Streltsova, E., Suieubayeva, S., Pshembayeva, D., they wrote about fuzzy logic approach in the modeling of sustainable tourism. Ziyadin, S., Litvishko, O., Dubrova, M., Smagulova, G., \& Suyunchaliyeva, M. in their research mentioned about Emerging economies play a key role in tourism development; strong tourism expenditure reflects enhanced connectivity, increased the global increased upcoming [19]. Veynberg, R.R., Timofeev, A., wrote about technological factor in the different aspects of economic sphere. There was always a common idea that technology is the future wave. [20].

The environmental safety of tourism ensures that the resources on which tourism depends are in a state of sustainable and healthy balance. In tourist areas and over time, natural resources, the environment, tourism and other elements of the system maintain a normal healthy structure and function. Some scientists argue that the environmental safety of tourism has become the main tool for measuring environmental impact and sustainable development, which has been the guiding ideology for regional long-term sustainable development. With regard to the critical approach, we analyze the environmental safety of tourism, identify critical factors and driving mechanisms, and find out how this affects the development of environmental safety in tourism. The search for solutions to these issues can not only provide a constructive perspective and development of solutions for practitioners, but also have significant implications for the sustainable development of regional tourism.

Another opposite site of the researching the eco-tourism in Kazakhstan were discussed by authors Kozhakhmetova, A., Zhidebekkyzy, A., Turginbayeva, A., \& Akhmetova, Z., they wrote about project managers often run similar projects in a different way under the influence of particular factors. [21]. Danabayeva, R., \& Shedenov, U. wrote about sustainable innovation development in the economic sphere hot it will comprimize the whole aspect of the economy, tourism as one of it. . N. Tovma wrote in the work Identified external and internal factors affecting the implementation of the digital economy, analyzed the totality of all factors affecting the development of the digital economy, identified the main development trends, in another aspect she researched about In the current conditions of the world economy development, the global trends of the "green economy" are the increase of energy efficiency in all spheres of the economy. It is noted that to facilitate the transition to a green economy, incentive measures should be created: concessional lending and taxation of modernization projects, subsidizing energy producers derived from alternative sources, and a system of "green" certification. Kazakhstan is the formation of a socially and environmentally oriented, profitable and competitive tourism industry that is able to supply the needs of tourists with various tourist services, bringing in revenues to the country and newly created jobs, including those defined with tourism in the sectors economy. Kazbekov, B. K., Bayandinova, S. M., \& Kazbekova, Z. wrote that Kazakhstan is a great emissioner of greenhouse gases and a contributor to global climate warming because of high carbon intensity. The Strategy of sustainable development, aimed to GDP energy consumption decrease, is adopted. [22]

Ecological model and ecosystem theory is used as a theoretical fundamental theory and provides a theoretical basis for the development of new assessment methods. On the other hand, the essence of this theory is that in a certain period of time in the ecosystem some elements, including organisms, environment and organisms, through the flow of energy, material circulation and transfer of information, eventually reach a highly adaptive, coordinated and unified state. Ecological tourism is perceived as an alternative to conventional tourism. 
Ecotourism focuses on local cultures, wild adventures, volunteering, personal growth and exploring new ways to live on our vulnerable planet. This is usually defined as travel to destinations where flora, fauna and cultural heritage are the main attractions .

Responsible ecotourism includes programmes that minimize the adverse effects of traditional tourism on the natural environment and increase the cultural integrity of the local population.

\section{Data and methodology}

\subsection{Data descriptions and analysis}

The strategic vision of ecotourism development in the Republic of Kazakhstan is the formation of the image and approval as a globally recognized tourist destination by 2020 (in the order of development of the national tourism program). The main long-term environmental trends in ecotourism are:

(a) Raising public awareness of environmental conservation and protection issues, enabling the development and implementation of tourism products "close to nature", which are environmentally sustainable: hiking, cycling, horse riding and bird watching;

(b) Economic changes caused by climate change, necessitating adaptation of local service providers, tour operators and transport companies to new conditions.

Ensuring proper management and coordination of tourism policy and development, public organizations in order to implement public policy in the field of ecotourism in Kazakhstan (SMART program).

S. Planned development of ecotourism in Kazakhstan (date of implementation 2017).

M. Increase the flow of visitors to Kazakhstan for ecotourism by 10-30\% (compared to today). Positive feedback from the client on the work done in the field of ecotourism. Increase in the share of local employment by 30-40\% in ensuring environmental safety of the region. Minimize costs by attracting investors to these areas.

A. For advertising media and their placement it is necessary to determine the budget, select media that meet the needs of the target audience segment, plan the placement and reserve a place in the materials placed on the selected media.

$\mathrm{R}$. They are characterized by qualitative indicators (number of tourist arrivals in the region, economic activity and its tangibility in the budget, multiplier effect, reduction of unemployment among the local population, etc.), growth of attractiveness of tourists, identification of new mechanisms for further planning of ecotourism development in the region, as well as comparison of the market before and after the work based on the analysis and segmentation of tourists (both internal and external). 2017

T. Period of commitment and implementation of the project after marketing planning

According for this results we can conclude that the main diagram of the different types of the eco-tourism in Kazakhstan is divided into several groups which are characterized the global aspect of the development of eco-tourism sphere in the whole. Most of the types are popular because of their opportunities. (Fig. 1) 


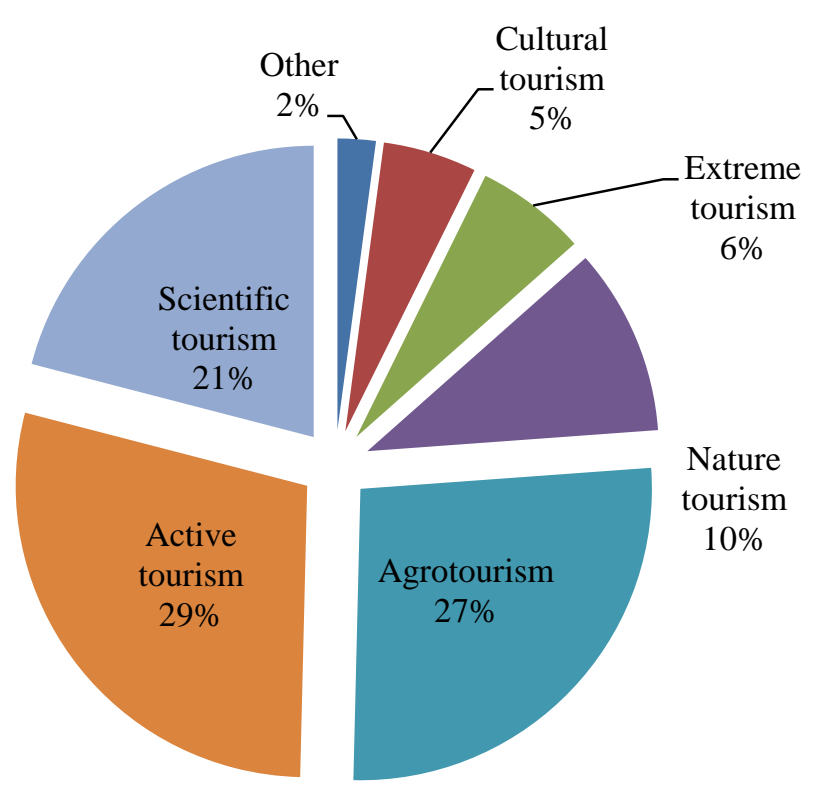

Fig 1. The diagram of different types of eco-tourism in Kazakhstan for the last 5 years.

Sustainability in tourism implies a positive overall balance between the environmental, socio-cultural and economic impacts of tourism, as well as the positive impacts of visitors on each other. Thus, those tourism activities that have the highest overall environmental, economic and social benefits are more sustainable. Sustainable tourism is a tourism that implies unlimited long-term maintenance of the resources on which it is based.

Ecotourism is often understood as other types of nature-oriented tourism. All of them are interconnected, but they are different in nature.

\subsection{Methodology}

The research uses a comprehensive approach. The following scientific methods are used: description, scientific abstraction and ascent from the private to the general one, comparison, analogy, analysis and synthesis, extrapolation to the whole territory of the regularities revealed in the model plots. Among private methods, statistical analysis, computer technology of information processing and SWOT analysis were used.

The work is an analysis of existing research on ecotourism as a component of ecotourism theory and practice. Central attention is paid to the types and objects of ecotourism, the main problems and aspects of its development in Kazakhstan are noted. 


\section{Results and discussion}

Problems of ecotourism market in Kazakhstan. Today, there are a number of problematic issues that would allow to achieve the planned goal of forming Kazakhstan as an international tourist center with a developed system of services and infrastructure:

1. Insufficient development of tourism and transport infrastructure. The material base of accommodation facilities, including hotels, resorts and sanatoriums, as well as sanatoriumresort facilities, has a high degree of moral and physical wear and tear. Currently, the scale of tourism, types, quality and supply of places for recreation of tourists do not meet international standards. Taking into account that the development of tourism is directly related to the state of transport infrastructure, a significant problem is the limited geography of passenger air and rail transportation, the lack of flexible benefits and discounts on tickets for all types of transport of group trips for tourists both domestic and inbound.

2. Low level of training, retraining and advanced training of personnel and lack of scientific basis for tourism. One of the main obstacles to the development of tourism is the lack of specialized tourism personnel serving this sphere. This applies not only to the lack of qualified personnel in the tourism industry, but also to the quality of training for the tourism industry.

Poor quality of tourism services. The problem is related to the previous one, as the low quality of services in this sphere leads to the low quality of services in the tourism industry. In addition, we are talking about the timing of processing tourist visas in Kazakhstan, registration procedures, customs and passport control of foreign tourists. The development of the ecotourism industry is mainly influenced by external factors, including the state of the world economy, legal regulation, economic and political situation in the country and abroad, and others (Table 2).

\section{Conclusion}

Expanding tourism in sensitive natural areas without adequate planning and management can threaten the integrity of ecosystems and local cultures. Increasing the number of visitors to environmentally sensitive areas can lead to significant environmental degradation. In addition, local indigenous communities and cultures can be damaged in many ways through the influx of foreign visitors and wealth. In addition, climate variability, exchange rates, and political and social conditions can make overreliance on tourism a risky business.

However, this growth also creates significant opportunities for both conservation and local communities. Ecotourism can provide much-needed revenues to protect national parks and other natural area-based facilities that may not be available from other sources.

In addition, ecotourism can provide a viable economic alternative to development for local communities with few other income-generating options. In addition, ecotourism can increase education and activity among travellers, making them more enthusiastic and effective conservation agents. 
Table 1. SWOT analysis.

\begin{tabular}{|c|c|}
\hline Strengths & Weaknesses \\
\hline - Availability of tourism industry & - Almost all infrastructure is located in \\
cities and large settlements; \\
- Legislative and regulatory framework for \\
the development of the tourism industry; \\
- High interest in ecotourism on the \\
international market; & - Infrastructure mismatch from the \\
- There are many guest house workers; & - There are no conditions for a multi-day \\
stay of tourists at the objects of interest; & - There is no mechanism to provide \\
- Unique culture and history of Kazakhstan; & subsidies, preferential duties and tax benefits to \\
- Availability of natural conditions and & investors; \\
protected areas; & - Ecotourism development approaches and \\
- Rich human resources; & policies are not formalized; \\
potential of the territory. & - Poor quality of roads to tourist facilities; \\
- High agricultural and natural-recreational & - Personnel training does not meet the real \\
needs of the market;
\end{tabular}

\section{References}

1. S. Ziyadin, A. Beyzhanova, A. Orazymbetova, R. Yessenzhigitova, IBIMA 2018 Vision 2020: Sustainable Economic Development and Application of Innovation Management from Regional expansion to Global Growth, 3080-3084 (2018)

2. A. Madiyarova, S. Ziyadin, A. Blembayeva, R. Doszhan, IBIMA 2018 - Vision 2020: Sustainable Economic Development and Application of Innovation Management from Regional expansion to Global Growth, 7990-7997 (2018)

3. T. L. Tazhibayeva, S. Zh. Isaldaeva, J. Geogr. Envir. Manag. 36(1), 56-64 (2019)

4. A. Kalinina, L. Pushkareva, A. Rybakova, Amazonia Investiga 8(22), 40-50 (2019).

5. B. Uriadova Promotion of ecotourism for poverty eradication and environmental protection (2012) 
6. S. Zh. Isaldaeva, About prospects of development of ecological tourism in Kazakhstan: materials of the international scientific conference of students and young scientists "World of science", 335-336. (2013)

7. A. B. Drozdov, Fundamentals of ecological tourism (2005)

8. M. R Arpentieva, Recreaching geography and development of ecological turism, 78-89 (2017)

9. M. B. Birzhakov, Introduction to tourism, Gerda, (2008)

10. Official website of the Committee of Tourism Industry of the Ministry of Industry and New Technologies of the Republic of Kazakhstan http://www.kit.gov.kz

11. E.V. Alekseeva, E.V. Dreval, Probl. Envir. Nat. Resour. 99-112 (2015)

12. B. V. Lapochkina, Int. Res. J., 5 (47),100-105 (2016)

13. V.A. Babikov, Tourism and regional development, 34-92 (2004)

14. O. A. Lavrennikova, N. P. Bochkareva, Innovation science 4-3 (2015)

15. K. S. Bricker, R. Black, S. Cottrell (ed.). Sustainable tourism and the millennium development goals (Jones \& Bartlett Publishers, 2013).

16. J. Qian, H. Shen, R. Law, Sustainability 10(3), 590 (2018).

17. C. M. Tepelus, R. C. Cordoba, Journal of Cleaner Production 13(2), C. 135-140. (2005).

18. S. Ziyadin, A. Borodin, E. Streltsova, S. Suieubayeva, D. Pshembayeva, Pol. J. Manag. Stud. 19(1), 492-504 (2019), DOI: 10.17512/pjms.2019.19.1.37

19. S. Ziyadin, O. Litvishko, Int. J. Civ. Engin. Techn. 10(2), 1055-1070 (2019)

20. R.R., Veynberg, A., Timofeev et al. Espacios 39(12), 3(2018)

21. A., Kozhakhmetova, A., Zhidebekkyzy et al. Econ. Soc., 12(2), 219-234 (2019)

22. R. Danabayeva, U. Shedenov, World App. Sci. J. 27(2), 178-182. (2013).

23. B. K. Kazbekov, S. M. Bayandinova, Z. Kazbekova, World App. Sci. J. 25(11), 1643-1648 (2013)

24. E. Vasilyeva, A. Mottaeva, E3S Web of Conferences, 91,08051, (2019) doi.org/10.1051/e3sconf / 20199108051

25. S. Ziyadin, G. Dauliyeva et al. Proceedings of the 31th International Business Information Management Association Conference, IBIMA 2017, 2065-2070 (2017)

26. P. P. Shaykenova, K. R. Mamutova Collection of articles of the All-Russian scientific-practical conference "Ecological and ethnographic tourism: formation, problems and prospects of development" (2009) 